\title{
Un soporte habitable. Cuando la pantalla de proyección se convierte en un espacio real.
}

\section{A habitable support. When de projection sreeen becomes a real space}

\section{Elena Mir}

Universidad de Valencia info@elenamir.com
Recibido 11/10/2020 Revisado 02/04/2021

Aceptado 02/04/2021 Publicado 30/04/2021

\section{Resumen:}

El soporte de proyección, junto a los avances tecnológicos y la hibridación entre arte y ciencia, se ha convertido en un espacio de experimentación abierto a ser conquistado y reconstruido. La tecnología, por tanto, ha conseguido que la instalación, gracias al uso de soportes de proyección inéditos, sea capaz de esculpir nuevos espacios capaces de reconfigurar la realidad, readaptándola y creando una nueva forma de expresión plástica. Es así como la pantalla, frágil y evasiva, todavía resulta difícil de atrapar en conceptos, pues los límites de esta nueva realidad flexible se muestran inabarcables. Sin embargo, existen trabajos donde el soporte se convierte en lugar, en espacio habitado, y el material se desvanece, se difumina, desaparece frente a nuestra mirada para brindarnos una nueva realidad, un nuevo espacio abierto a la experiencia más allá de lo emocional, psicológico y perceptivo, un espacio que se presenta palpable, a través del que nos asomamos, como si de una ventana se tratase, para ver más allá de lo imaginable, cuestionándonos la realidad misma y concediéndonos el privilegio de expandir nuestros propios límites de comprensión.

\section{Sugerencias para citar este artículo,}

Mir, Elena (2021). Un soporte habitable. Cuando la pantalla de proyección se convierte en un espacio real. Tercio Creciente (Monográfico extraordinario V), (pp. 225-238), https://dx.doi.org/10.17561/rtc.extra5.5809

MIR, ELENA. Un soporte habitable. Cuando la pantalla de proyección se convierte en un espacio real. Tercio Creciente (Monográfico extraordinario V) abril 2021, pp. 225-238, https://dx.doi.org/10.17561/rtc.extra5.5809 


\section{Abstract:}

The projection support, beside to technological advances and the hybridization between art and science, has become a space for experimentation open to being conquered and rebuilt. Technology, therefore, has made the installation, thanks to the use of new projection supports, capable of sculpting new spaces being able to reconfigure reality, readapting it and creating a new form of plastic expression. This is how the screen, fragile and elusive, is still difficult to catch in concepts, because the limits of this new flexible reality are immeasurable. However, there are works where the support becomes a place, an inhabited space, and the material fades, dispels and disappears in front of our gaze to give us a new reality, a new space open to experience beyond the emotional, psychological and perceptual, a space that appears palpable, through which we look out, as if it were a window, to see beyond the imaginable, questioning reality itself and granting us the privilege of expanding our own limits of understanding.

\section{Palabras Clave:}

Instalación, soportes, proyección inmaterial, hibridación, realidad

\section{Key words:}

Installation, supports, inmaterial projection, hybridization, new realities

Sugerencias para citar este artículo,

Mir, Elena (2021). Un soporte habitable. Cuando la pantalla de proyección se convierte en un espacio real. Tercio Creciente (Monográfico extraordinario V), (pp. 225-238), https://dx.doi.org/10.17561/rtc.extra5.5809

MIR, ELENA. Un soporte habitable. Cuando la pantalla de proyección se convierte en un espacio real. Tercio Creciente (Monográfico extraordinario V) abril 2021, pp. 225-238, https://dx.doi.org/10.17561/rtc.extra5.5809 


\section{Capacidades del soporte: Nuevos paradigmas y significados}

Cuando miramos la luz que se manifiesta a través de una pantalla de proyección, nos convertimos en espectadores de luz. Una luz que queda contenida en la superficie del material que toca, formando parte de él y convirtiéndose a éste, a su fisicidad, a sus características.

Es por ello que las capacidades del soporte nos trasladan a nuevos paradigmas y significados, sin embargo, a pesar del enorme protagonismo que las pantallas tienen en nuestra era tecnológica, el soporte se muestra todavía evasivo e inestable y muchas veces resulta difícil atraparlo en conceptos. Aún así es indudable la cantidad de opciones que nos permite entre las que cabe destacar.

Como el fenómeno de la proyección desde su aparición hasta la actualidad, ha ido creando una nueva conciencia sobre los soportes, que con el tiempo y fruto de la experiencia e investigación, han aportado a las obras cualidades capaces de crear profundidad, tridimensionalidad e incluso imágenes holográficas.

Estas hibridaciones entre arte y ciencia también han dado como resultado el uso de materiales inéditos dejando todo un legado de artistas que han incorporado la proyección a sus obras, y que han realizado un estudio absoluto de las pantallas, sirviendo estos materiales de forma decisiva a dar sentido al fin último del trabajo. Mirando la pantalla, nos damos cuenta de la importancia del material sobre el que se proyecta; pues no es lo mismo una pantalla de tela opaca, que una tela traslúcida, no es igual proyectar sobre humo que sobre el agua pulverizada, no da igual si el soporte está perforado, o si su superficie es reflectante o incluso transparente. Nada tiene que ver proyectar sobre una bola de algodón, que sobre un árbol o un edificio o incluso sobre el propio cuerpo. Pues el discurso que se transcribe y sobreimprime a esa piel luminosa, es por sí mismo un recurso necesario que nos incita a acercarnos, a entrar en contacto con la obra, a entender más allá de su forma y contenido.

En relación a los objetos que son empleados en el arte como contenedores y recipientes de ideas, recae una interconexión íntima que se establece entre esos elementos y la proyección. Bachelard, nos habla de la expansión del espacio que se produce en los casos en los que conectamos "lo de dentro con lo de fuera", en la experiencia objetual y sus relaciones: Dar su espacio poético a un objeto, es darle más espacio que el que tiene objetivamente. De esta forma atendemos a una fórmula donde la suma de ambos elementos sugiere la aparición de un tercero, que modifica los sentidos originales de representación propias del objeto, y reconstruye un nuevo significado. Amplificando así sus posibilidades: psicológicas, perceptivas y multisensoriales. 
También encontramos una percepción háptica que se identifica con una experiencia activa del entorno, donde la mirada recurre a más sentidos que los puramente visuales, funcionando los propios ojos como órganos táctiles. Esta apreciación háptica acuñada por Alois Riegl, surge a través de entender el concepto táctil como una experiencia limitada, considerando el espacio háptico como una sensación de atracción hacia lo que vemos mucho más plural en sensaciones.

También se establece una relación multimedia, donde todos los elementos narrativos presentes: pantalla, objeto y su interacción con el video, expanden sus significados individuales a nuevos conceptos narrativos, convirtiendo el soporte en un elemento significante, trascendente y dinámico, capaz de contener y expandir las propiedades de la proyección.

\section{El soporte se desvanece: La pantalla se hace invisible}

Dentro de este juego de relaciones entre la pantalla y la proyección, nos interesa adentrarnos en aquellas obras en las que el soporte se desvanece, aquellas manifestaciones en las que la pantalla se hace invisible.

Y es así que la pantalla transmuta, no solo desde un plano emocional, psicológico y perceptivo, sino también físico, pues el soporte plano convencional traspasa la pantalla a un espacio cinético y arquitectónico, tridimensional... dando lugar a un espacio propio, envolvente e inmersivo, que pone alerta nuestros sentidos y nos deja a merced de un espacio multisensorial.

Aquí el soporte desaparece, se invisibiliza. La imagen luz queda contenida y fijada en una nueva realidad que absorbe el soporte y lo inmaterializa creando un nuevo espacio de experiencia, propio y único.

Ante estas nuevas realidades: expansiones del espacio real, la pantalla se muestra como ventana, creando así un espacio propio, tangible y habitable. 


\section{El espacio habitado: La proyección y el soporte redefinen la realidad}

Cuando la pantalla se invisibiliza e inmaterializa y el soporte pasa inadvertido, éste queda convertido en realidad misma. La imagen-luz penetra dentro de esta piel luminosa para adueñarse de ella y conquistarla, creando espacios donde el soporte se desvanece y se convierte irremediablemente a merced del contenido que sobre él se proyecta.

Por lo tanto, la pantalla, en un inicio inerte y sin vida, ahora queda habitada, actuando como contenedor de una nueva realidad, abandonando así el espacio virtual para convertirse en un espacio lleno, incuestionablemente habitado, ocupado por una nueva presencia que se vuelve tan real como la realidad misma.

De esta forma el soporte actúa como catalizador que posibilita la creación de nuevos espacios de experiencia.

\section{Entre lo real y lo virtual: Explorando los límites}

Tal y como decía Ivan Sutherland "El desafío es hacer que ese mundo se vea real, actúe real, suene real, se sienta real."

El soporte y la proyección, por lo tanto, necesitan redefinir los conceptos sobre la REALIDAD.

Las obras que analizamos:

-Trabajan en las intersecciones entre arte, ciencia, tecnología y experiencia.

-Juegan con nuestra percepción y nuestros sentidos y nos sumergen en una experiencia multisensorial.

-Abordan una nueva realidad flexible, que cuestiona la virtualidad para convertirse en espacio lleno, habitado y conquistado, ampliando las dimensiones de lo que consideramos real, donde encontramos la verdadera entidad del soporte, capaz de crear y contener más allá de lo imaginable.

-Redefinen las fronteras entre lo real y lo virtual, explorando los límites de nuestra percepción y de la propia realidad, un lugar que cuestiona aquello que entendemos por real e ilusorio. 
ISSN: $2340-9096$

https://doi.org/10.17561/rtc.extra5.5809

\section{(5)}

\section{Artistas:}

\section{Peter Sarkisian}

El trabajo de Peter Sarkisian, artista de video y multimedia americano, intenta eliminar cualquier referencia al video para liberar las imágenes de las trampas de la tecnología. Desafía así a los espectadores a olvidarse del medio y perderse en las ideas humanas y vivas inmanentes en su obra. Su pieza White Water, presenta la imagen de una mujer desnuda flotando serenamente sobre agua lechosa dentro de un recipiente físico. De fondo escuchamos el sonido relajante del vaivén del agua. La obra entraña un espacio físico que ha quedado invadido por la presencia de una realidad que invisibiliza el soporte, y que genera un juego ilusorio que intenta jugar con la realidad. Narraciones que serpentean en los límites de la virtualidad.

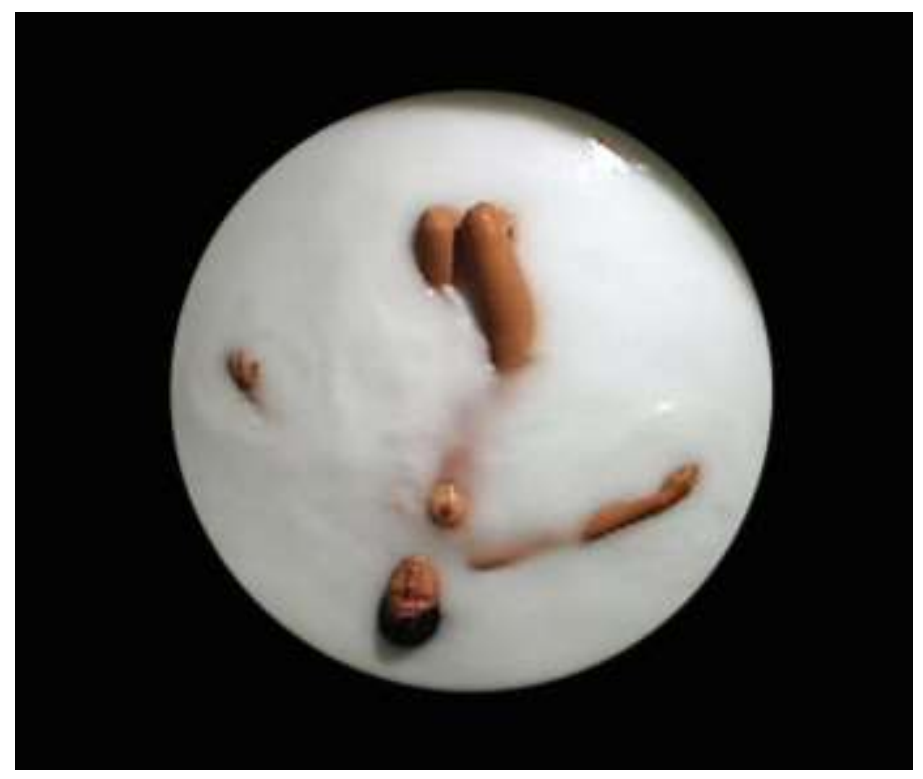

Peter Sarkisian (1999) White Water. 


\section{Studio Azurro}

El grupo italiano Studio Azzurro trabaja en propuestas pioneras interactivas y es uno de los principales exponentes en el campo de la hibridación artística en el lenguaje audiovisual y las nuevas tecnologías.

En su instalación Dove va tutta 'sta gente, dedicada al tema de la migración, las puertas de vidrio se abren amigablemente a nuestra llegada, sin embargo, suponen un umbral infranqueable para los individuos representados, cuyos cuerpos se mueven lentamente, lanzándose con todas sus fuerzas e impactando contra las barreras sólidas que se oponen a dejarles pasar, generando una división de privilegios. El dispositivo interactivo se refiere a una complejidad de las relaciones humanas y el espacio de instalación se transforma en un "lugar antropológico", en el que los movimientos de cierre y apertura no siempre responden de la manera esperada. Es así que nuevamente el espacio se muestra como contenedor de una realidad social, política y a la vez física.

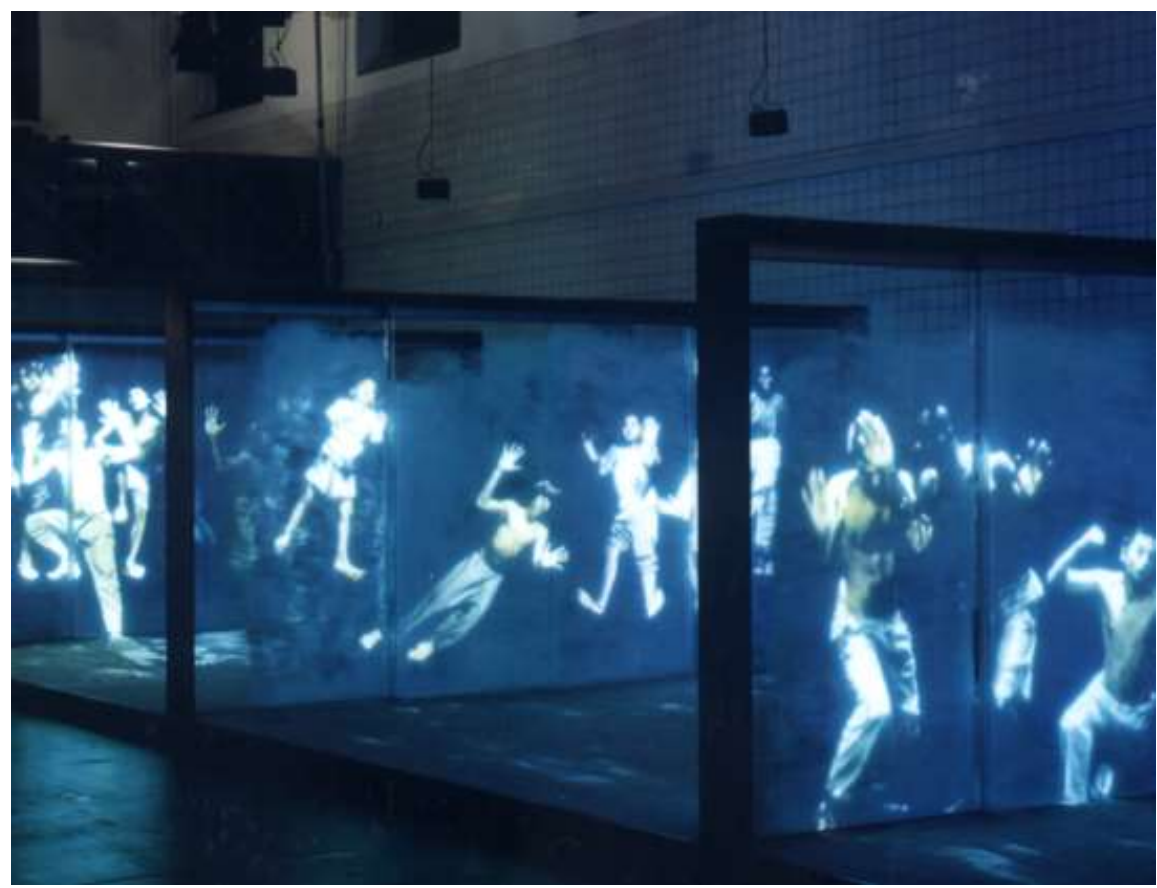

Studio Azurro (2000) Dove va tutta 'sta gente? 
ISSN: 2340-9096

https://doi.org/10.17561/rtc.extra5.5809

\section{क}

\section{Refik Anadol}

El artista de origen turco Refik Anadol, replantea nuevos enfoques sobre las posibilidades de la representación dentro de la intersección entre tecnología avanzada y el arte contemporáneo. En su obra Melting Memories, Anadol nos habla sobre la materialidad de los recuerdos, mostrándonos la enorme capacidad del arte por realizar interpretaciones estéticas de los movimientos motrices del interior de un cerebro humano. Recogiendo datos de los mecanismos neurológicos de control cognitivo, que mide mediante los cambios de actividad de las ondas cerebrales, nos ofrece pruebas de como funciona el cerebro con el tiempo, creando estructuras visuales multidimensionales a través de los algoritmos que le aportan todos estos datos. De esta forma su obra trabaja en la fusión entre neurociencia y tecnología, cuestionando el surgimiento de un nuevo espacio en el que la inteligencia artificial no está reñida con la individualidad y la intimidad.

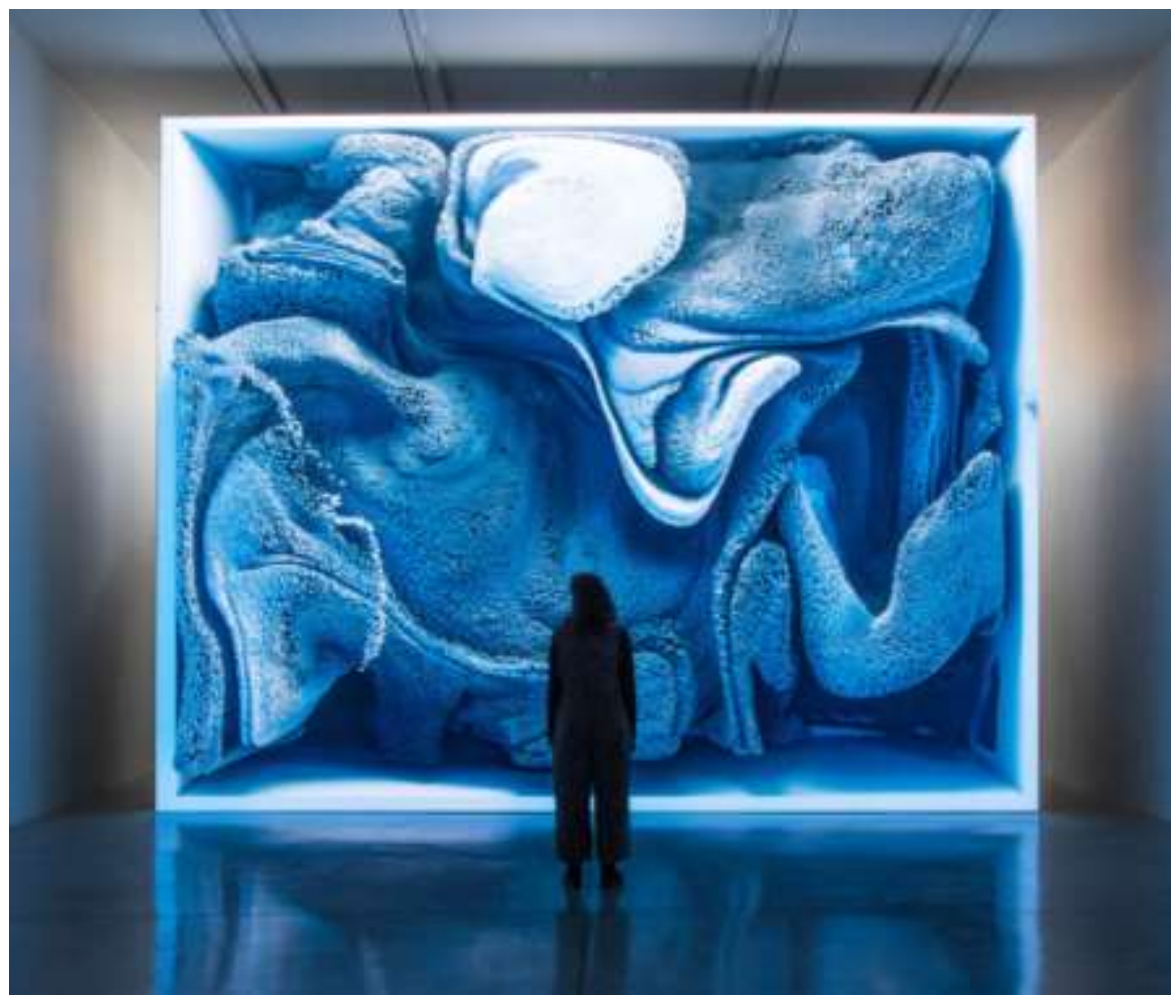

Refik Anadol (2018) Melting Memories. 


\section{Yiyun Kang}

En los trabajos de la artista coreana Yiyun Kang, el soporte sobre el que se apoya la luz se convierte en habitáculo, en un espacio de interrelación entre sujeto y proyección, del que surge un nuevo espacio que cobra vida dentro de la propia pantalla, creando una realidad ficticia. Su trabajo Beyond the Scene, es sin duda un ejemplo de construcción de un espacio dentro del soporte. Las proyecciones muestran el residuo visual del trabajo corporal que diversos performers han realizado sobre un tejido, de tal forma que estas imágenes al ser proyectadas sobre las enormes pantallas parecen realmente contener un individuo en su interior. Estas huellas hechas por el cuerpo, que tan sólo se sustentan en las luces y sombras creadas por su movimiento, difuminan la idea de realidad. Este diálogo que nos conecta directamente con el interior de la obra, juega con la alteración de nuestra percepción, cuestiona nuestros límites sensoriales y nos sugiere la pantalla como un recipiente real, no solo proyectivo sino con capacidad para ser habitado y para mostrarnos una nueva realidad.

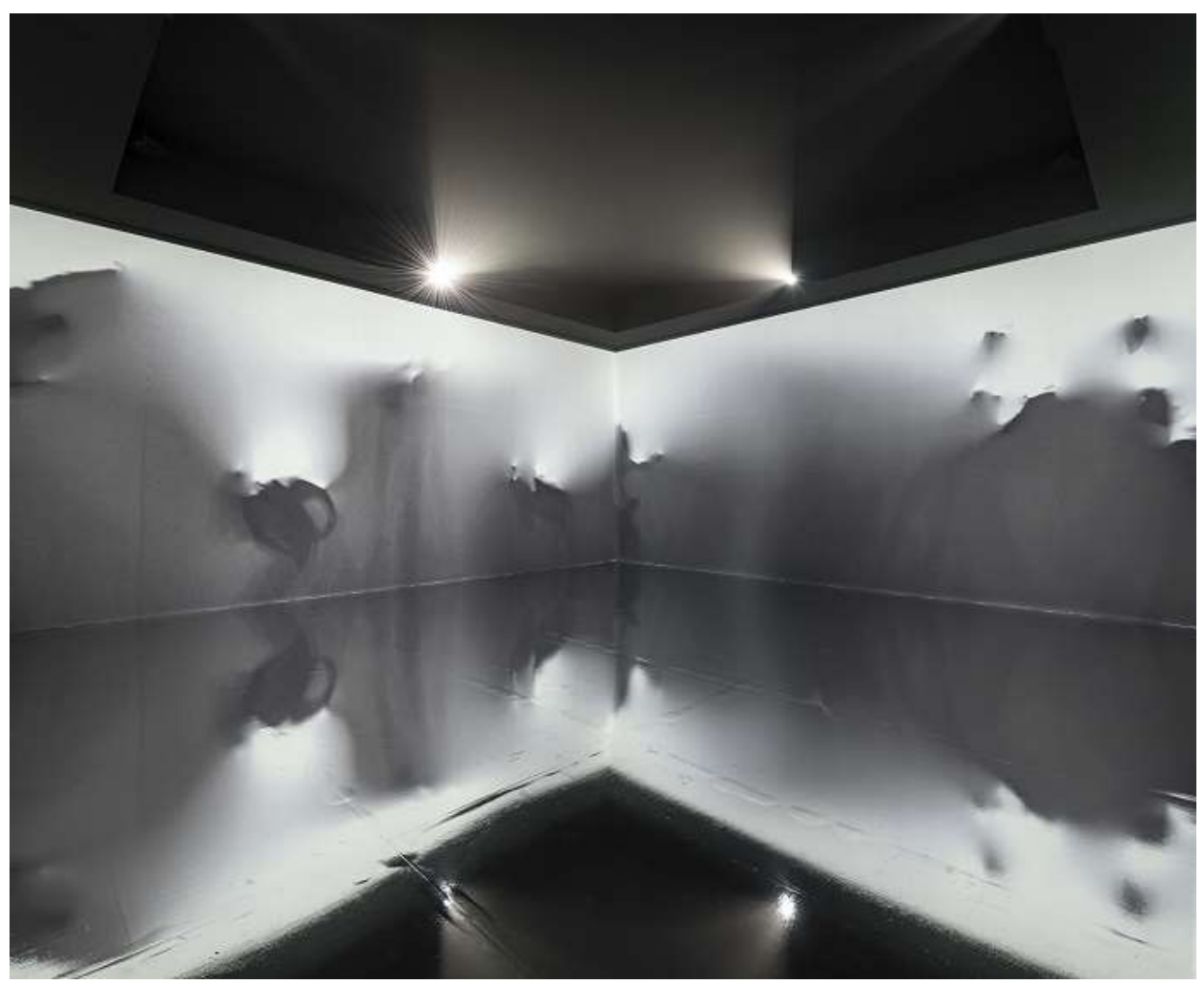

Yiyun Kang (2020) Beyond the scene. 
Tercio Creciente

ISSN: 2340-9096

https://doi.org/10.17561/rtc.extra5.5809

क
Revista de Estudios en Sociedad, Artes y Gestión Cultural
Monográfico

Extraordinario V

Abril 2021

+ Artistas:

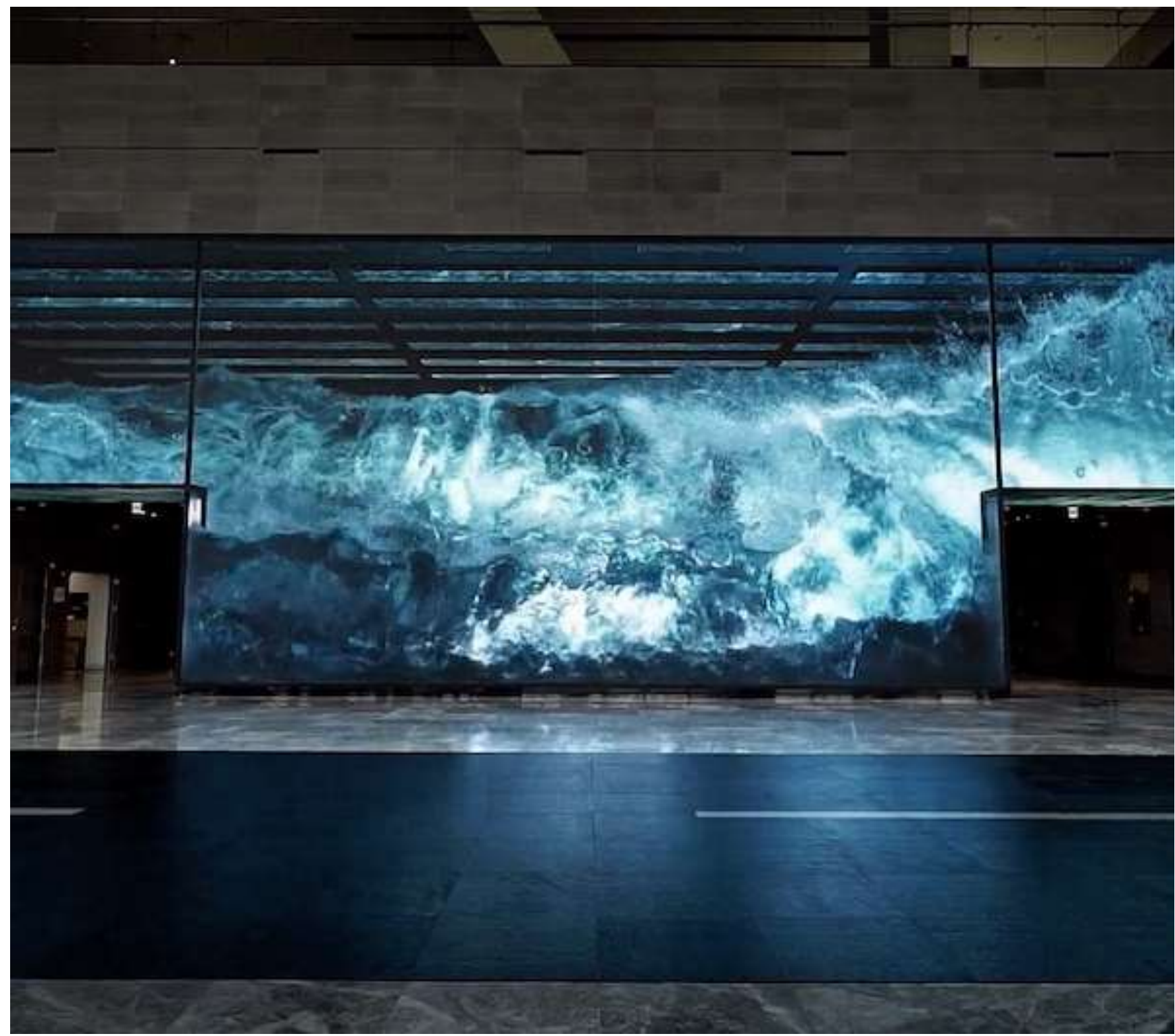

D'istrict (2019) The infinity wall. 


\section{Tercio Creciente}

ISSN: $2340-9096$

https://doi.org/10.17561/rtc.extra5.5809

(1) $\infty$
Revista de Estudios en Sociedad,

Artes y Gestión Cultural
Monográfico

Extraordinario V

Abril 2021

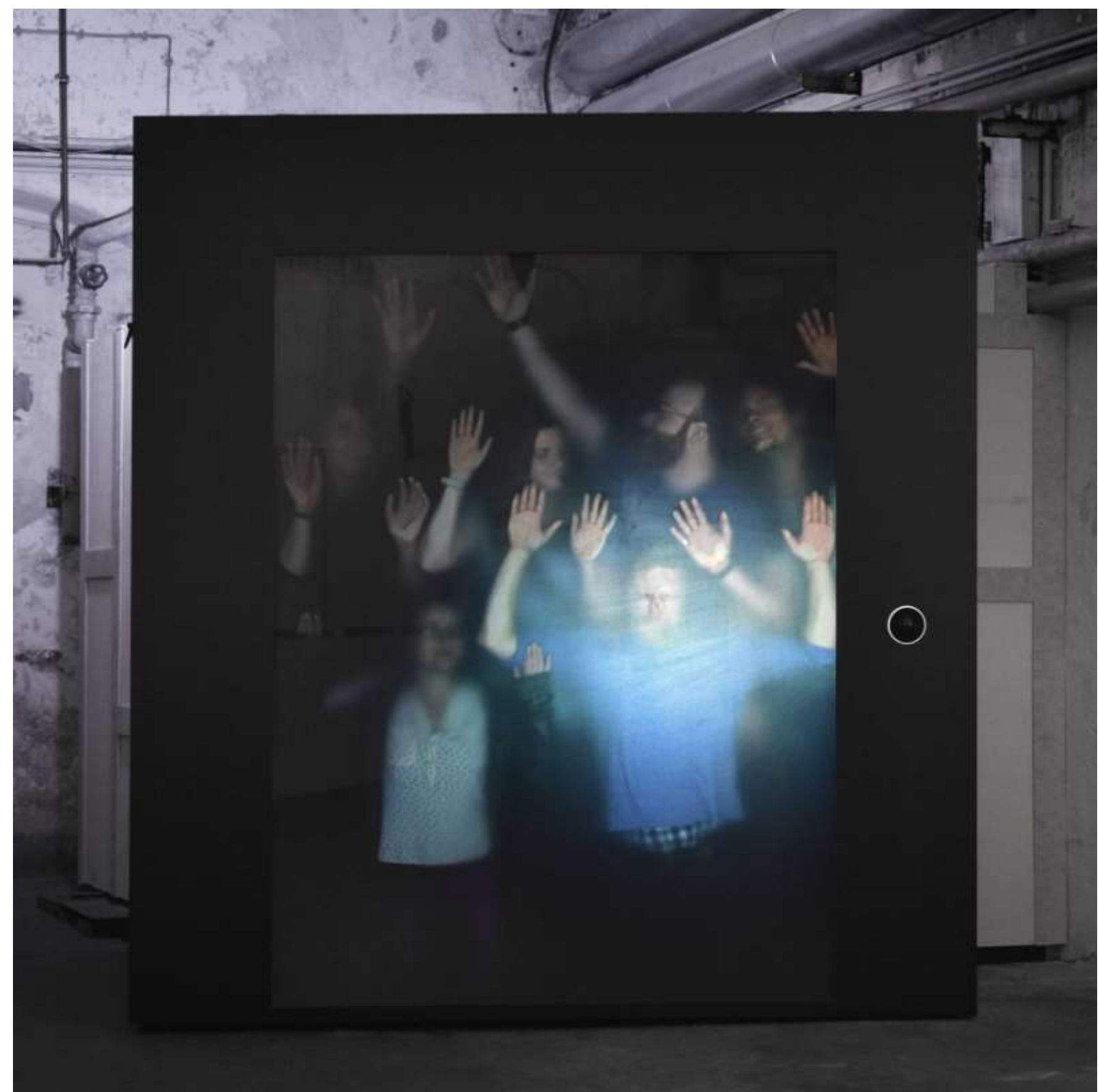

Blendid (2017) Touch me. 


\section{Tercio Creciente}

ISSN: 2340-9096

https://doi.org/10.17561/rtc.extra5.5809

क
Revista de Estudios en Sociedad, Artes y Gestión Cultural

Monográfico

Extraordinario V

Abril 2021

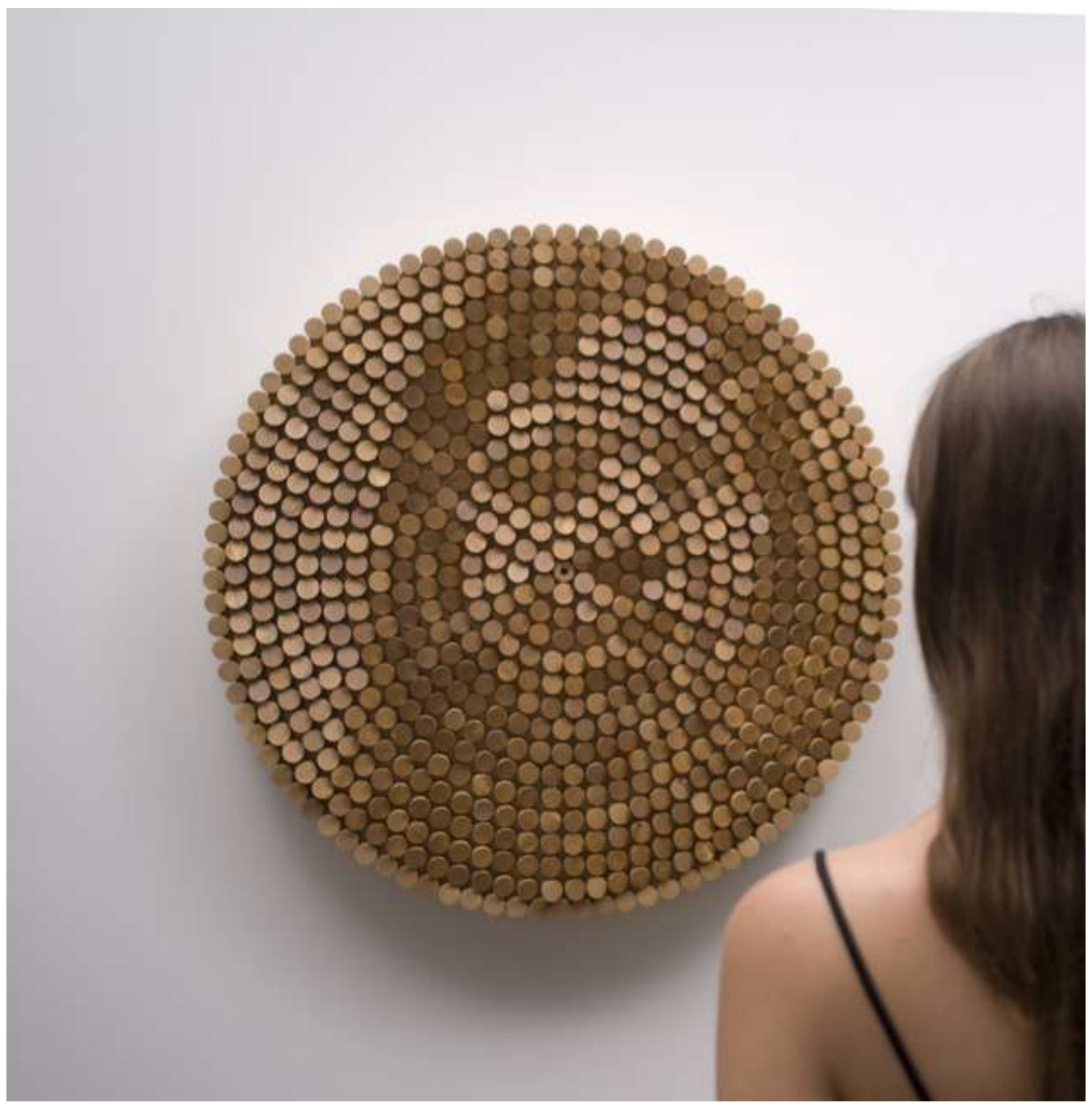

Daniel Rozin (2007) Peg mirror. 


\section{Tercio Creciente}

ISSN: 2340-9096

https://doi.org/10.17561/rtc.extra5.5809

(1)

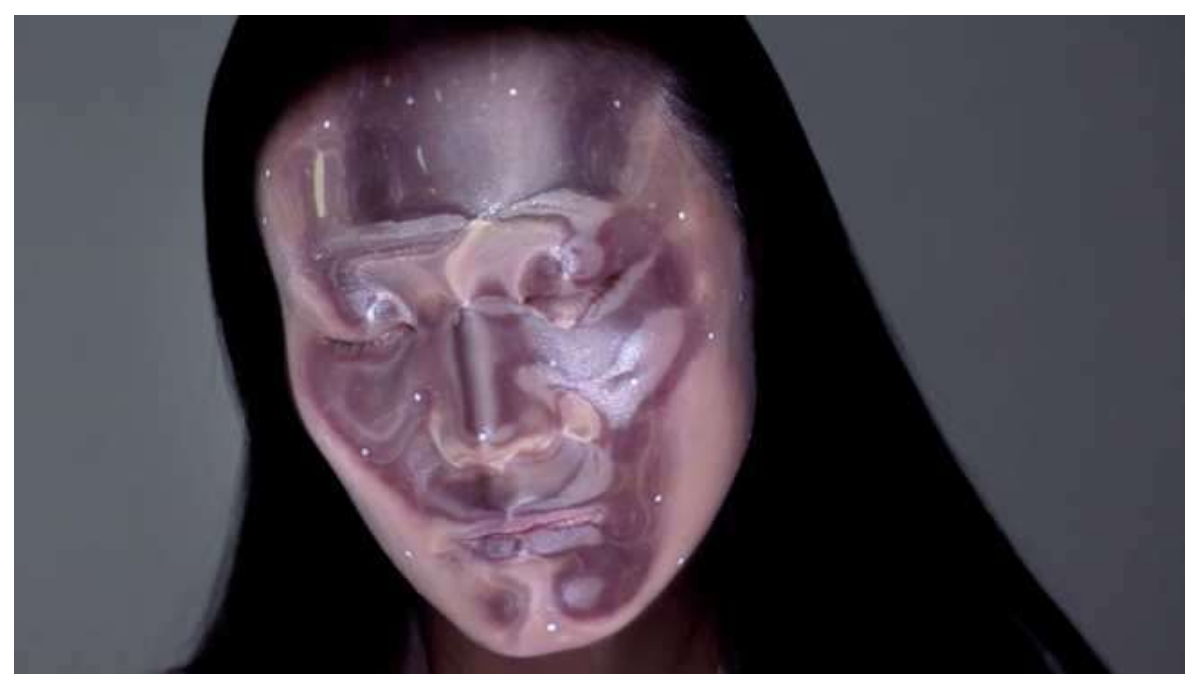

Nobumichi Asai (2015) Omote.

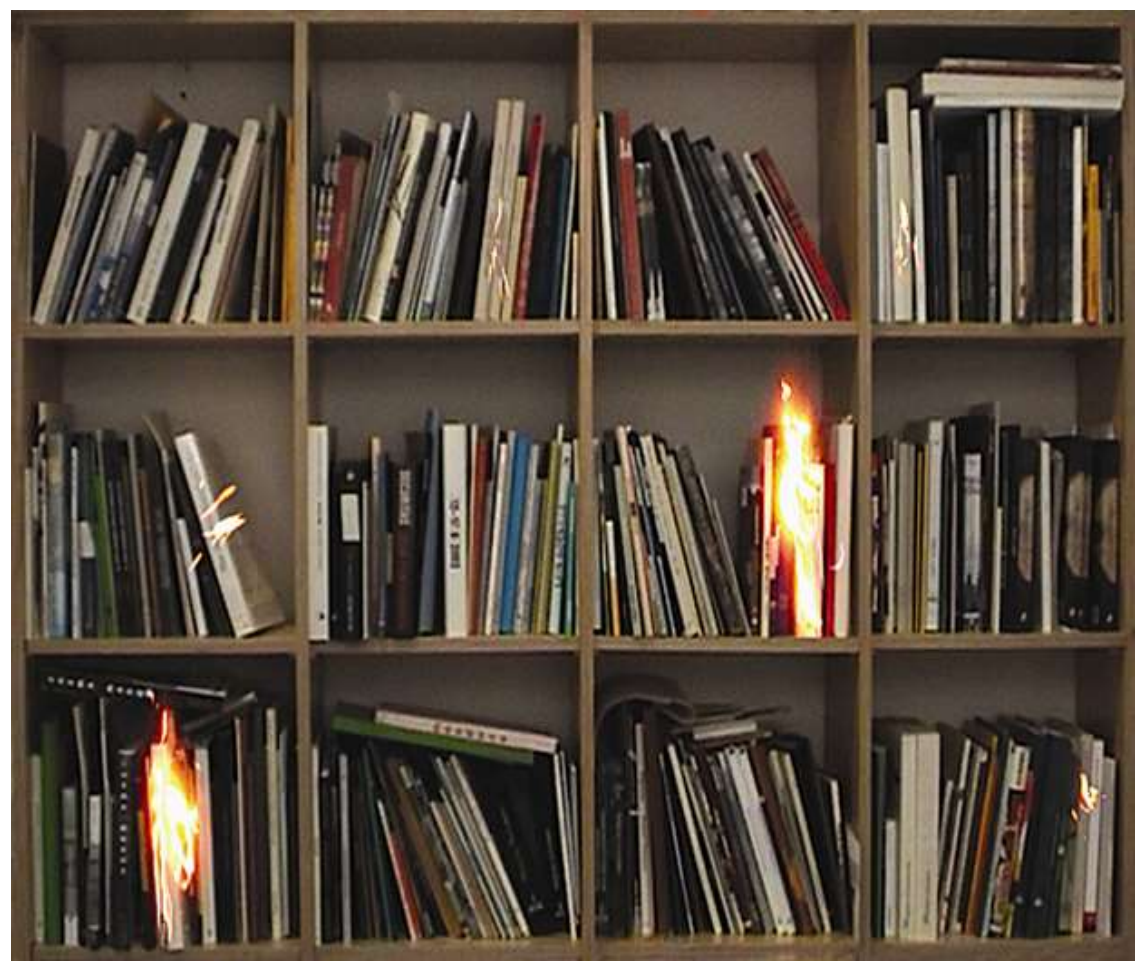

Eugenio Ampudia (2009) Fuego Frío I y II. 


\section{Conclusiones}

La tecnología ha conseguido que no solo el cincel y el martillo sean capaces de esculpir las formas, sino, que la luz, junto al uso de soportes de proyección cada vez más inmateriales, unido a los avances tecnológicos y a la hibridación entre arte y ciencia, han conseguido que sea un material maleable, capaz de reconfigurar la realidad, readaptándola, y con ello creando toda una nueva forma de entender el mundo y, en consecuencia, una nueva forma de expresión plástica.

Las nuevas manifestaciones y sus nuevas fronteras todavía lejos de clasificaciones y en constante expansión, se descubren en estos soportes híbridos entendiendo, por tanto, el sentido de la imagen-tecnológica, como un nuevo significado expandido de la imagen-luz y de la imagen-movimiento.

Es por tanto incuestionable que cada vez más los límites entre lo virtual y lo real se difuminan, encontrando representaciones en los que ambos conceptos parecen el mismo, ampliando la idea simplista que hoy día tenemos de la realidad, y encontrando muestras de una verdad tecnológica todavía en proceso de construcción.

\section{Referencias}

BACHELARD, Gastón. 1975. La poética del espacio, México D.F.: Fondo de Cultura Económica.

BAUDRILLARD, Jean. 1990. Videosfera y sujeto fractal. En AAVV. Videoculturas de fin de siglo, Madrid: Cátedra.

BREA, José Luis. 1997. Nuevos soportes tecnológicos, nuevas formas artísticas. [Consulta: Agosto 2020]. Disponible en: http://www.geocities.ws/ciberespao/nuevossuportestecnologicos.doc

COULTER-SMITH, Graham. 2009. Deconstruyendo las instalaciones, Madrid: Brumaria.

MÁRQUEZ, Israel. 2015. Una genealogía de la pantalla: del cine al teléfono móvil, Barcelona: Anagrama.

VALÉRY, Paul. 1999. Piezas sobre arte, Madrid: Visor.

VIRILIO, Paul; LOTRINGER, Sylvère. 2008. Pure War, New York: Semiotext(e). 